\title{
COVID 19 and Orthodontics-The New Normal
}

\author{
Dr. Litesh Singla, $\mathrm{MDS}^{1 *}$, Dr. Divya Singla, $\mathrm{MDS}^{2}$
}

${ }^{1}$ Assistant Professor, Department of Orthodontics, Dr. HSJIDS \& Hospital Panjab University, Sector 14, Chandigarh, 160014, India
${ }^{2}$ Private Practitioner, Department of Orthodontics, Panchkula-134109, Haryana, India

DOI: $\underline{10.36347 / \text { sjds.2020.v07i09.003 }}$

| Received: 06.09.2020 | Accepted: 13.09.2020 | Published: 17.09.2020

*Corresponding author: Dr. Litesh Singla

Abstract

Review Article

WHO on $11^{\text {th }}$ March 2020 declared COVID 19 as pandemic and since then this disease has become a public health emergency of international concern. The latest recommendation for prevention of COVID 19 includes avoidance of personal contact and keeping social distance. But this recommendation cannot be implied in health care works including orthodontics clinics. All the orthodontist and dental assistants are at very high risk of disease. This review should aid in increasing awareness, fortify contamination control, and forestall cross-transmission inside the orthodontic society.

Keywords: COVID 19, pandemic, orthodontist, social distance.

Copyright @ 2020: This is an open-access article distributed under the terms of the Creative Commons Attribution license which permits unrestricted use, distribution, and reproduction in any medium for non-commercial use (NonCommercial, or CC-BY-NC) provided the original author and source are credited.

\section{INTRODUCTION}

Coronavirus disease 19 or COVID-19 was first identified in December 2019 and was confirmed in Wuhan, China. The disease is caused by SARS COV 2 (severe acute respiratory syndrome coronavirus). WHO on $11^{\text {th }}$ March 2020 declared the disease as pandemic and since then this disease has become a public health emergency of international concern [1]. This pandemic has affected the entire society. On 11 February 2020 WHO finally called this novel viral pneumonia as "Corona Virus Disease (COVID 19)." Dentistry is an occupation fallen under the high-risk category because of close contact with the patient and dental procedures generating aerosols.

Patients suffering from this COVID 19 exhibited common symptoms such as fever, cough, tiredness with unusual CT in the chest. In some cases, even sputum production, headache, hemoptysis, and diarrhea were observed (Figure-1) [2, 3]. The COVID19 pathogen affects older patients with critical respiratory diseases which require special attention for older males [4].

Orthodontists meet a number of patients in a day. Strict infection control in orthodontic clinics is a major area of concern. By far most of the orthodontic patients are youngsters [5, 6]. Various studies have revealed that infected youngsters may be asymptomatic. This discovery rings the alert of a possible risk i.e. treating asymptomatic patients and spreading disease inside the orthodontic center. Besides, aerosol generation is common in the orthodontic clinics which itself is an affirmed course of disease transmission.

The goal of this article is to answer the orthodontists on the development, epidemiology, transmission, dangers, and safeguards during this COVID emergency. This review should aid in increasing awareness, fortify contamination control, and forestall cross-transmission inside the orthodontic society. 


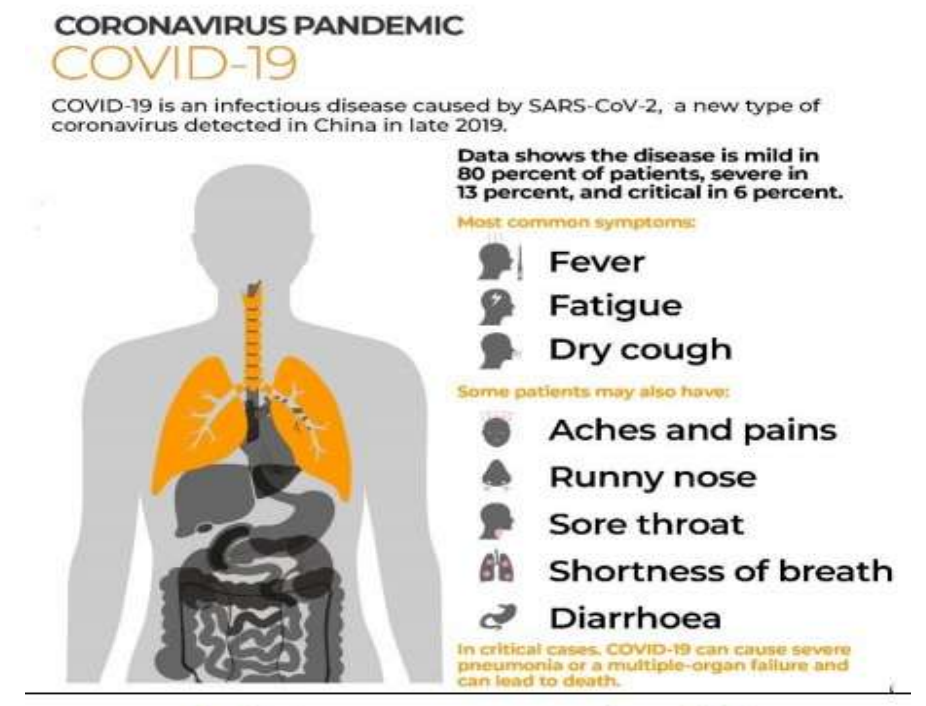

Fig 1: Most common symptoms in Covid-19

\section{Characteristic of COVID 19 Virus}

A huge, single, plus-stranded RNA is a characteristic feature of the Coronaviruses family, which belongs to the Coronaviridae family, and of the Nidovirales family. $\alpha-\mathrm{CoV}, \beta-\mathrm{CoV}, \gamma-\mathrm{CoV}$, and $\delta$ $\mathrm{CoV}$ are the four coronavirus genera [7, 8]. The coronavirus disease most often infects humans and vertebrates. $\alpha-\mathrm{CoV}$ and $\beta-\mathrm{CoV}$ infect rodents and humans mostly with the respiratory, gastrointestinal, and central nervous system. Though birds are primarily contaminated with $\delta-\mathrm{CoV}$ and $\gamma-\mathrm{CoV}$. The nucleotide sequence similarity is less than $80 \%$ between COVID 19 and SARS-CoV or MERS-CoV. The infection caused by COVID 19 is more fatal and spreads faster than the two other coronaviruses $[9,10]$.

\section{Routes of Transmission of COVID-19}

Detailed knowledge of the routes of transmission of this infection is important for taking preventive steps. Coronavirus is primarily distributed directly via (sneeze, droplet inhalation, and cough) [11]. Respiratory viruses, according to the intensive investigations, may be spread from person to person either by direct or indirect touch or by coarse or tiny droplets. COVID-19 is also directly or indirectly transmitted by saliva [12]. COVID-19 may be aerial according to the studies disclosed/suggested via aerosols emitted during medical procedures. Today's public concern is the other transport routes such as aerosol transmission route, fecal-oral transmission route, and water transmission path. Further research on these fields is required.

\section{Routes of Transmission of COVID-19 in Dental Clinics}

Dental practitioners, workers, and patients are vulnerable to pathogenic microorganisms, bacteria, and viruses that attack and infect the respiratory and oral cavity. Dental procedures include the high risk of COVID-19 chances of infection due to the complexity of the dental procedure. This includes direct contact with patients before, during, and after the dental procedure (Figure-2). Apart from dental sharp objects, they are exposed to saliva, blood, and other body fluids. The infected COVID19 dental patient can leave pathogenic microorganisms/viruses while coughing. Non-use of masks, indirect contact with infected instruments, and/or surfaces in the atmosphere can also contribute to transmission [13].

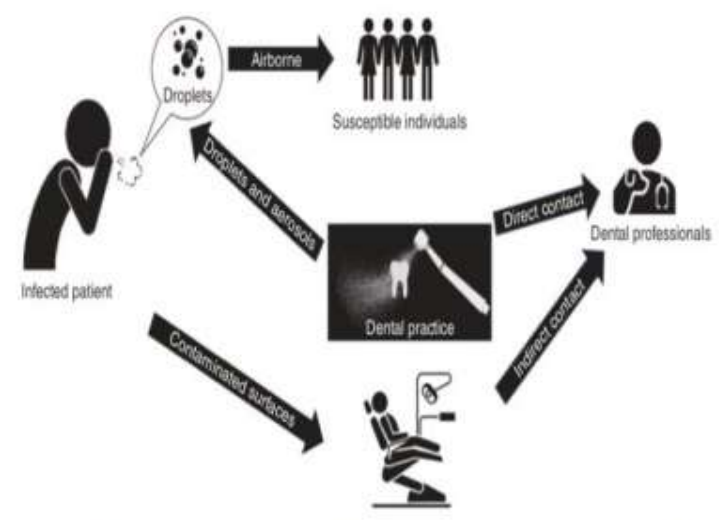

Figure 2. Illustration of routes of transmission COVID19 in dental clinics and hospital. (Transmission routes of COVID-19 and controls in dental practice Peng et al.)

\section{Disease Transmission and Orthodontic Practice:}

The latest recommendation for prevention of COVID 19 includes avoidance of personal contact and keeping social distance. But this recommendation cannot be implied in health care works including orthodontic clinics. Thus, all the orthodontist and dental assistants are at very high risk of disease.

Cross-transmission has been reported with other viral diseases i.e. Hepatitis B and Hepatitis C. Orthodontists have been found to have $2^{\text {nd }}$ highest incidence of Hepatitis B. Cross transmission of 
COVID19 within the orthodontic facility has not been reported but still, the risk exists

Possible sources of contamination in orthodontic setup:

1. Saliva: Various studies have already reported that saliva is a rich source of SARS-COV-2 [14].

Tongue, Buccal mucosa have been found to have ACE2 receptors (receptors for COV2) which increases the chances of transmission by the orofaecal route [15]. The human oral cavity is an incubator of the virus [16].

2. Generation of Aerosols: Various orthodontic procedures like bonding, bracket positioning, and debonding require the use of air rotor handpiece and ultrasonic scalers which leads to aerosols and splatter generation. Rautemaa $\mathrm{R}$ et al., [17] reported that the aerosols with microbes may reach up to 2 meters from the patient suggesting that the aerosols may contaminate the whole operatory. Bentley C.D [18] in 1994 did a study using a fluorescent dye with a high-speed air rotor and observed that the dye reached more than 2 meters from the patient's mouth. Aerosols of smaller size may remain in the air for a longer duration and increases the risk of penetration in the lungs which is a big threat in this COVID emergency.

3. Instruments: All the instruments used in orthodontic clinic should be sterilized before using them. Instruments used in orthodontic clinics come in contact with blood, saliva, gingival tissues including band seaters, removers, scalers, etc. Improper handling and disinfection of orthodontic instruments may compromise the contamination control protocols.

\section{Protocols for Prevention in the Orthodontic Setting 1. Sterilization Protocols and minimizing chances of exposure \\ Orthodontists ought to be acquainted with how} COVID 19 is possibly spread, distinguish patients with SARS-CoV-2 disease, and what extra-protection ought to be received during clinical practice to forestall the transmission of the virus. Standard infection control measures need to be altered considering the spread of the pandemic. All the surfaces of the clinic should be wiped with disinfectants and instruments should be sterilized. PPE should be worn and remove with safety. PPE disposal should not be ignored. Evaluation of health care providers and all the assistants should be done regularly. Oral rinse with chlorhexidine before treatment has been found to reduce the number of microbes. Aerosol production if necessary should be avoided. If necessary, respirators, N95, and face shields should be used both by the dentist as well as the dental assistant. Hand hygiene should be reinforced by everyone working in the operatory. Adequate ventilation of the operatory as well as the waiting area is suggested.

\section{Pre Appointment Triage}

Multiple patients should not be appointed for a single day. Appointments should be given after teleconsultation so as to maintain social distancing in the clinics.

The following questions should be asked before finalizing the appointments:

a. Travel history.

b. Symptoms of the disease i.e. fever, cough, cold, etc.

c. Contact with COVID patient.

d. Participation in gatherings.

\section{Alternatives to aerosol generating procedures (AGP) in the orthodontic setting}

The orthodontic treatments involve the use of high-speed air turbine or slow speed rotary drill, 3 in 1 air/water syringe, and enamel preparation with ultrasonic or air abrasion equipment. By the use of high-volume suction (HVE) and/or rubber dam to restrict aerosol and bio-impact, these procedures are still considered to be AGP and suitable PPE should be equipped along with adequate decontamination protocols in the procedure.

\section{a. Debond}

The bracket removal process is not considered an AGP. An ultrasonic scaler or 3 in 1 air/water spray should be avoided as well as a handpiece, (high speed or slow speed, with or without water coolant). Orthodontic patients with poor oral hygiene, consideration should be given to remove brackets alone and to carefully trimm the adhesive by hand using: $i$. band removing pliers, ii. Mitchell's trimmers or hand scalers, iii. Adhesive removing pliers. With tooth brushing, the leftover composite at the enamel surface may be lost over time. When using debonding pliers there is no more loss of enamel than with slow speed Tungsten Carbide bur ride dry [19], but one should be careful not to rip the enamel surface. Pliers should only be used to scrape the adhesive on rear teeth, not the incisors in which Mitchell's hand scaler trimmer should also be used. If significant restorations are present on the posterior teeth, consider placing a roll of cotton wool on the occlusal surface before applying some force with the plier.

\section{b. Repair of Brackets Mid Treatment}

If residual composite can be removed by hand as described above, this can allow a new bracket to be positioned (using Non-AGP bonding technique). Alternatively, inserting a premolar or molar band using GIC, or bypassing the debonded tooth using a dead coil or sleeve on the wire, or using sectional wires to the debonded tooth would be feasible. 


\section{c. Aligner Attachments}

If positioned using bonding technique, positioning of the aligner attachments may be considered non-AGP. Removal of attachments would be non-AGP by using the adhesive removal method as suggested and will only be known as AGP if the residual composite is removed with a handpiece.

\section{d. Impression Taking}

The impression process is not an AGP in itself, but carries a risk of gag or cough reflex which is a recognized aerosol attack. An intraoral scan may be advantageous where convenient (though this does not remove the possibility of gag/cough). All impressions should be sterilized in compliance with the HTM01-05 protocol [20] to establish a secure move to the casting and appliance processing laboratory.

\section{Management of Orthodontic Emergency}

Experts decide whether to remain accessible or to handle emergencies. The appointments may be deferred based on single Nations guidelines [21].
Concerning any pain or issues related to appliances, the patients should be strictly monitored. Frequent breakages will extend the care process and result in a lack of trust in the appliance or operator. Pandemic guidelines released by the Government should be strictly adhered to during COVID-19. The dentists should see certain cases as an abscess or permanent pulpitis which cannot be delayed. Orthodontists should assess the serious matters other than general dental calculations based on a video call or photo message [22]. Internet Assistance: WhatsApp Messenger (Facebook, Inc, Mountain View, California) has been creating instant messaging software since 2009. They swiftly spread among people of all ages. They are used for personal relationships, entertainment, research, and also as a virtual place of group interaction. Using new technologies, orthodontic emergencies should be treated progressively. Digital aid and Whatsapp could be used as a helpful tool in the first step. Images, video calls, and Whatsapp messages/calls are used as virtual support. How different emergencies are handled is illustrated in Table- 1 below.

Table-1: Different scenarios of emergencies and ways to resolve them

\begin{tabular}{|l|l|l|}
\hline $\begin{array}{l}\text { Removable } \\
\text { appliances }\end{array}$ & Functional. & $\begin{array}{l}\text { If the fit of the appliance is not proper or if it is broken, a photo can be sent to the } \\
\text { orthodontist and suspend the use }\end{array}$ \\
\cline { 2 - 3 } & Aligners & $\begin{array}{l}\text { If broken or lost can get back to the previous and ask the clinician. The following } \\
\text { clinician's indication can remain on current/go with treatment. }\end{array}$ \\
\cline { 2 - 4 } $\begin{array}{l}\text { Fixed } \\
\text { appliances }\end{array}$ & $\begin{array}{l}\text { The non-removable } \\
\text { appliances such as } \\
\text { (straight appliance) } \\
\text { customizable preforms on e-commerce sites. }\end{array}$ & $\begin{array}{l}\text {-Loose Bracket: Initially send the photo to the dentist, remove with tweezer } \\
\text { eventually. } \\
\text {-Poking distal wire: Send a photo, use wax, disinfected nail clipper/hardware } \\
\text { cuter can be used to cut. } \\
\text {-Poking ligature: Photo can be sent to an orthodontist, wax to be used, or use the } \\
\text { eraser of a pencil to push it back. } \\
\text {-If there is a periodontal abscess around molar band: Send photo, symptomatic } \\
\text { therapy with paracetamol, eventually prescription of an antibiotic. } \\
\text {-The picture should be taken every 3-6 weeks, if the patient feels pain or } \\
\text { swelling, see as an emergency in the dental office and remove the appliance } \\
\text { eventually. }\end{array}$ \\
\hline
\end{tabular}

\section{CONCLUSION}

Although no confirmed cases of COVID-19 cross-transmission are currently recorded within the dental setting, orthodontic practitioners need the utmost diligence to minimize the risk of transmission. This analysis confirms the critical steps needed to minimize infection, as illustrated in the section on findings above. Although the virus is still evolving, awareness is limited and it is difficult to provide detailed and thorough best practice guidelines as such. Further studies are necessary to inform future practice.

\section{REFERENCES}

1. World Health Organization Novel coronavirus (2019-nCoV): situation report11. https://www.who.int/docs/defaultsource/coronaviruse/situation-reports/20200131sitrep-11-ncov.pdf?sfvrsn=de7c0f7_4
2. Huang C, Wang Y, Li X, Ren L, Zhao J, Hu Y, Zhang L, Fan G, Xu J, Gu X, Cheng Z. Clinical features of patients infected with 2019 novel coronavirus in Wuhan, China. The lancet. 2020 Feb 15;395(10223):497-506.

3. Guan WJ, Ni ZY, Hu Y, Liang WH, Ou CQ, He JX, Liu L, Shan H, Lei CL, Hui DS, Du B. Clinical characteristics of 2019 novel coronavirus infection in China. MedRxiv. 2020 Jan 1.

4. Chen N, Zhou M, Dong X, Qu J, Gong F, Han Y, Qiu Y, Wang J, Liu Y, Wei Y, Yu T. Epidemiological and clinical characteristics of 99 cases of 2019 novel coronavirus pneumonia in Wuhan, China: a descriptive study. The Lancet. 2020 Feb 15;395(10223):507-13.

5. Chan JF, Yuan S, Kok KH, To KK, Chu H, Yang J, Xing F, Liu J, Yip CC, Poon RW, Tsoi HW. A familial cluster of pneumonia associated with the 
2019 novel coronavirus indicating person-toperson transmission: a study of a family cluster. The Lancet. 2020 Feb 15;395(10223):514-23.

6. Rothe C, Schunk M, Sothmann P, Bretzel G, Froeschl G, Wallrauch C, Zimmer T, Thiel V, Janke C, Guggemos W, Seilmaier M. Transmission of 2019-nCoV infection from an asymptomatic contact in Germany. New England Journal of Medicine. 2020 Mar 5;382(10):970-1.

7. Nakagawa K, Lokugamage KG, Makino S. Viral and cellular mRNA translation in coronavirusinfected cells. InAdvances in virus research 2016 Jan 1 (Vol. 96, pp. 165-192). Academic Press.

8. Fan Y, Zhao K, Shi ZL, Zhou P. Bat coronaviruses in China. Viruses. 2019 Mar;11(3):210.

9. Al-Tawfiq JA, Zumla A, Memish ZA. Coronaviruses: severe acute respiratory syndrome coronavirus and Middle East respiratory syndrome coronavirus in travelers. Current opinion in infectious diseases. 2014 Oct 1;27(5):411-7.

10. Bai Y, Nie X, Wen C. Epidemic prediction of 2019-nCoV in Hubei province and comparison with SARS in Guangdong province. Available at SSRN 3531427. 2020 Feb 4.

11. Bai Y, Nie X, Wen C. Epidemic prediction of 2019-nCoV in Hubei province and comparison with SARS in Guangdong province. Available at SSRN 3531427. 2020 Feb 4.

12. Belser JA, Rota PA, Tumpey TM. Ocular tropism of respiratory viruses. Microbiology and Molecular Biology Reviews. 2013 Mar 1;77(1):144-56.

13. Ireland AJ, Hosein I, Sherriff M. Enamel loss at bond-up, debond and clean-up following the use of a conventional light-cured composite and a resinmodified glass polyalkenoate cement. The European Journal of Orthodontics. 2005 Aug 1;27(4):413-9.

14. To KK, Tsang OT, Yip CC, Chan KH, Wu TC, Chan JM, Leung WS, Chik TS, Choi CY,
Kandamby DH, Lung DC. Consistent detection of 2019 novel coronavirus in saliva. Clinical Infectious Diseases. 2020 Feb 12.

15. Xu H, Zhong L, Deng J, Peng J, Dan H, Zeng X, Li T, Chen Q. High expression of ACE2 receptor of $2019-\mathrm{nCoV}$ on the epithelial cells of oral mucosa. International journal of oral science. 2020 Feb 24;12(1):1-5.

16. Ge ZY, Yang LM, Xia JJ, Fu XH, Zhang YZ. Possible aerosol transmission of COVID-19 and special precautions in dentistry. Journal of Zhejiang University-SCIENCE B. 2020 Mar 16:18.

17. Rautemaa R, Nordberg A, Wuolijoki-Saaristo K, Meurman JH. Bacterial aerosols in dental practice-a potential hospital infection problem? Journal of hospital infection. 2006 Sep 1;64(1):7681.

18. Bentley CD, Burkhart NW, Crawford JJ. Evaluating spatter and aerosol contamination during dental procedures. Journal of the American Dental Association. 1994 May;125(5):579.

19. Ireland AJ, Hosein I, Sherriff M. Enamel loss at bond-up, debond and clean-up following the use of a conventional light-cured composite and a resinmodified glass polyalkenoate cement. The European Journal of Orthodontics. 2005 Aug $1 ; 27(4): 413-9$.

20. Freeman J. Testing decontamination equipment in dental practice. Dental Nursing. 2012 Dec;8(12):772-9.

21. Caprioglio A, Pizzetti GB, Zecca PA, Fastuca R, Maino G, Nanda R. Management of orthodontic emergencies during 2019-NCOV.

22. Popat H, Thomas K, Farnell DJ. Management of orthodontic emergencies in primary care-selfreported confidence of general dental practitioners. British dental journal. 2016 Jul;221(1):21-4. 